Please do not remove this page

RMIT

UNIVERSITY

\title{
Formation of hollow granules from liquid marbles: Small Scale experiments
}

Eshtiaghi, Nicky; Liu, Jaques; Hapgood, Karen

https://researchrepository.rmit.edu.au/esploro/outputs/9921857674401341/filesAndLinks?institution=61RMIT_INST\&index=null

Eshtiaghi, N., Liu, J., \& Hapgood, K. (2010). Formation of hollow granules from liquid marbles: Small Scale experiments. Powder Technology, 197(3), 184-195. https://doi.org/10.1016/j.powtec.2009.09.013

Document Version: Submitted Version

Published Version: https://doi.org/10.1016/j.powtec.2009.09.013

Repository homepage: https://researchrepository.rmit.edu.au

(C) 2009 Elsevier B.V. All rights reserved.

Downloaded On 2023/04/27 01:11:54 +1000

Please do not remove this page 
Citation:

Eshtiaghi, N, Liu, J and Hapgood, K 2010, 'Formation of hollow granules from liquid marbles: Small Scale

experiments', Powder Technology, vol. 197, no. 3, pp. 184-195.

\title{
Formation of Hollow Granules from Liquid Marbles: Small scale experiments
}

\author{
Nicky Eshtiaghi, Jacques J.S. Liu and Karen P. Hapgood \\ Monash Advanced Particle Engineering Laboratory, \\ Department of Chemical Engineering \\ Monash University \\ Melbourne VIC 3800, Australia \\ Email: Karen.Hapgood@eng.monash.edu.au
}

\begin{abstract}
Research into formation of hollow granules from liquid marbles is an emerging field in hydrophobic granulation. A liquid marble is formed by a network of self-assembled hydrophobic powder around a droplet, and this paper investigates the conditions required for forming hollow granules from a liquid marble precursor.
\end{abstract}

Single drops of fluid were produced using a syringe and placed onto loosely packed powder beds of hydrophobic powders. Liquid marbles formed from several powder/liquid combinations were dried at several conditions to investigate the drying conditions required for formation of a stable hollow granule.

The formation of stable hollow granules was found to depend on drying temperature and binder concentration. For HPMC and PVP binder, formation of hollow granule is proportional to binder viscosity and for HPC binder, this relationship is constant. Different combinations of powder and binder at both drying temperatures $-60^{\circ} \mathrm{C}, 100^{\circ} \mathrm{C}$ - had mixed success rates in forming hollow 
granules, but generally the success rate was improved by using higher drying temperatures, smaller particles or higher viscosity binder fluids.

Keywords: Hollow granule, liquid marble, non-wetting, hydrophobic granulation, dry water.

\section{Introduction}

Hollow granules can be formed from hydrophobic powders by "solid spreading nucleation" [1] where the powder spreads around a template drop and the interior liquid is subsequently dried to form a hollow granule. The nuclei formed by solid spreading are also known as "liquid marbles" [2, 3] and "dry water" [4], and are used in cosmetic [4] and pharmaceutical formulations [1].

The pre-specified structural properties of hollow granules allow simultaneous control of granule size and structure, excellent flow, good compression for tabletting and fast dissolution rate. These granules are ideal for pharmaceutical products with a high concentration of a hydrophobic drug. Research into formation of hollow granules via either melt granulation [5] or via hydrophobic liquid marbles $[1,6]$ is an emerging field in hydrophobic granulation.

Solid spreading nucleation can be used to create hollow pharmaceutical granules suitable for compression into tablets [1]. Powder shell formation experiments were performed in a $2 \mathrm{~L}$ highshear mixer with 70 mass $\%$ of a submicron hydrophobic powder (contact angle $>90^{\circ}$ ) and $78 \%$ w/w water, which was atomized over 7-8 minutes into the mixer. In addition, $20 \%$ microcrystalline cellulose and $4 \%$ hydroxypropyl cellulose binder were added as hydrophilic excipients components plus $1 \%$ sodium lauryl sulfate as a surfactant. By drying the liquid marbles to remove internal fluid, 
stable spherical hollow granules were formed. The presence of excipients and surfactants did not prevent liquid marble formation or self-assembly of the particles at the drop interface since the hydrophobic model drug powder constituted $90 \%$ of the batch on a volume basis. Moreover, the excipients stabilized the powder shell to allow the hollow structure to be preserved during drying [1]. Apart from this one paper, there are no further studies on hollow granule formation from liquid marble precursors.

Bhosale et al. [7] studied the strength of liquid marble formed with PTFE (7-12 $\mu \mathrm{m})$ and 2 types of fumed silica powder, which had been treated with hexamethyldisilazane and dimethyldichlorosilane. Bhosale et al. suggested that high surface area nanoparticle materials like Aerosil create more uniform powder shells though uniform coverage of the liquid -vapor interface. They found that nano-powder shells form an "elastic" membrane that makes these liquid marbles mechanically robust in comparison with conventional liquid marbles made from larger particles. We expect that liquid marbles formed from nano-particles may be able to withstand higher compressive stresses during drying, and may be more likely to form a hollow granule.

Dandan and Erbil [8] determined the evaporation rate of graphite liquid marble and found that graphite liquid marbles had a much longer life time than a pure water droplet of the same size. The presence of graphite retarded the evaporation of water and extended the time required for the liquid to be completely evaporated. Increasing the relative humidity of the medium increases the evaporation resistance. For larger droplets, the lifetime was determined by diffusion controlled evaporation [8]. In comparison to Bhosale et al. [7] study, they found the graphite liquid marble evaporation rate was $7 \%$ lower compared to PTFE liquid marbles, which indicated that the liquid 
marble life time is extended by using small particles (e.g. graphite $10-20 \mu \mathrm{m}$ ) rather than larger particles (e.g. PTFE (5-7 $\mu \mathrm{m})$.

Polymeric binder is required to avoid the liquid marble collapsing after drying, as the binder forms solid bridges between the particles during drying which give strength to the powder shell. The physical properties of the binder and the drying temperature are both expected to be important in avoiding granule collapse. Drying of liquid marbles is expected to show some similarities with drying of liquid drops containing solutes. Fundamental studies of the phenomena occurring during the droplet drying process were reported by Charlesworth \& Marshall [9]. They developed a technique where an individual droplet was suspended in a controlled air stream, and the weight and temperature were recorded during drying in parallel with visual observations of the appearance and size of the droplet (see Figure 1). They used an aqueous solution of an inorganic salt droplet in relatively slow rates of evaporation (moderate air temperatures and velocities). The first period of drying was characterized by evaporation from a free liquid surface which is similar for all droplets regardless of the solute or drying conditions. After further drying, crystals formed at the bottom of droplet and gradually formed a crust around the droplet. After completion of the crust formation, drying depended on the solutes and the surrounding air temperature. Charlesworth \& Marshall [9] categorized these features into two main sections: air temperature above or below the boiling point of solution. In this study, we are interested in drying a single droplet in air at a temperature below the boiling point of solution. For this case, three different sub-categories were defined [9] (see Figure 1):

a) If the crust is rigid and porous, the air-liquid interface retreats between pores and the appearance does not change (I) 
b) If the crust is rigid but non-porous, fracture phenomenon occurring on the crust allow air to enter the particle and the air-liquid interface returns to the crust surface under the influence of capillary forces. There are three possible conditions after fracturing:

I. If fracture remains open, further formation of solid occurs out from particle surface (IIb) or within the crust structure (IIa).

II. If the fracture closes, the supply of air would be disrupted and the liquid interface once more retreats into the crust interstices. As the amount of liquid decreases, successfully smaller pores are emptied (crystal grows (IIc))

c) Crust is pliable and impervious. Rupture by implosion could eventually occur as the skin thickens and stiffens (III).

Charlesworth and Marshall's study [9] as summarized in Figure 1 is also presumed to be applicable for liquid marble drying, as the outer shell of powder in a liquid marble can be assumed to be similar to the first step of drying from a liquid surface. After further drying and shrinkage, a solid shell-like crust is produced. The permeability of the powder shell and binder matrix will determine whether there are enough pores to allow the interior liquid to be vaporized freely, and thus which of the cases shown in Figure 1 will occur for the drying of liquid marbles.

Walton and Mumford [10] also classified the various types of particle morphology produced at two different temperatures $\left(70^{\circ} \mathrm{C}, 200^{\circ} \mathrm{C}\right)$. They used a single droplet drying technique with a droplet contained dissolved solids under controlled air temperature, humidity and velocity in a simulated spray dryer. Their study demonstrated that both the chemical and physical nature of the material are important in determining particle morphology and the pliable or plastic nature of skin is 
related to its chemical and/or physical structure [10]. Polymeric materials tended to form a shriveled thin-walled hollow particle. Particles with a polymeric skin decreased in size without any rupture of the skin surface during initial drying period suggesting that the skin is porous. By increasing the concentration of solute in droplet, the particle diameter tended to stabilize as the particle skin (crust) adopted a more permanent structure, and resulted in a decrease in particle distortion, surface rupture and internal bubble nucleation.

At lower drying temperatures after complete drying, particles tend to shrivel and deform, and some signs of internal bubble nucleation and particle inflation appeared [10]. An increase in drying temperature from $70^{\circ} \mathrm{C}$ to $200{ }^{\circ} \mathrm{C}$ increased the rate of heat and mass transfer experienced by both droplet and particle increased. This resulted in shorter drying times and more violent drying behavior which produced particles with a greater tendency to inflate, shrivel and in some cases explode. At $200^{\circ} \mathrm{C}$, internal bubble nucleation was rapidly formed and the bubbles expanded to violently distort, and eventually rupture. This caused the particle to collapse, shrive and then reinflate. This cycle was repeated three or four times until the internal moisture had evaporated (see Figure 2).

In some cases, evaporation of a residual liquid inside partially dried particles caused the liquid to foam and bubble causing internal blistering within the larger parent particle [10]. After drying, the hardened foam gave a blistered appearance to particle. High surface area powders with good gas absorption properties increased the internal porosity of the particles by adsorption of gases during drying. The internal structure of these particles showed much larger vacuoles [10]. 
This paper will investigate what happens to the liquid marble as the template drop is removed during drying for a variety of powder-fluid combinations and a range of drying temperatures. The aim is to identify the right powder-binder combination and the right drying temperature to produce stable hollow granules from liquid marble nuclei.

\section{Materials and Methods}

Glass ballotini spheres $\left(\mathrm{d}_{50}=65 \mu \mathrm{m}, \mathrm{AH} / \mathrm{AG}\right.$ grade, $\rho=2.5 \mathrm{~g} / \mathrm{cm}^{3}$, Potters Industries Pty Ltd.) were used to form liquid marbles. In order to make the glass beads hydrophobic, SIGMACOTE solution (chlorinated organopolysiloxane in heptane, Sigma Aldrich Pty Ltd.) was used. Two additional hydrophobic powders were used: Polytetra fluoroethylene (PTFE) with four different particle size grades $\left(1,12,35\right.$, and $100 \mu \mathrm{m}, \rho=2.1 \mathrm{~g} / \mathrm{cm}^{3}$, Sigma Aldrich Pty Ltd), and fumed silica Aerosil R974 with primary particle size of 12nm (Degussa, Germany).

Several different binder solutions were used: PVP (poly-vinyl pyrrolidone (40T), Sigma Aldrich Pty Ltd), HPMC (Hydroxy Propyl Methyl Cellulose, Premium LV, E3, The DOW Chemical Company), and HPC (Hydroxy Propyl Celloluse, 100,000 Mw, Sigma Aldrich Pty Ltd). Concentrations between 2-18\% on a weight basis were used. Fluid viscosities were measured using a rotational viscometer (Visco Basic Plus, Fungilab, Barcelona).

Liquid marbles were prepared by releasing a droplet from a $1 \mathrm{~mL}$ syringe with a $18 \mathrm{~g}$ needle approximately $2 \mathrm{~cm}$ above a loosely packed powder bed. The droplets were then agitated using the syringe needle tip on the surface of the powder bed to form a multilayered liquid marble. At least 10 
liquid marbles were dried for each individual combination of temperature, powder and binder. To try to estimate the liquid to solid for each powder-liquid combination, the average weight of 10 liquid marbles was measured using an analytical balance, and compared to the average weight of 10 drops of the fluid. The powder shells were very light, approximately $0.1 \mathrm{mg}$ each, and the random variations during weighing were the same or larger than the weight of the powder shell. We were unable to obtain sensible results for the $\mathrm{L}: \mathrm{S}$ ratio and this data is therefore not reported.

Several drying methods have been used: air drying at $24{ }^{\circ} \mathrm{C}$ and $31 \%$ humidity, freeze drying at $50{ }^{\circ} \mathrm{C}$ and $300 \mathrm{mmHg}$ (Bench Top Freeze Dryer, OPERON Co., Ltd.) and oven drying in a fanforced $60 \mathrm{~L}$ laboratory oven (S.E.M.(SA) Pty. Ltd) at $60^{\circ} \mathrm{C}, 80^{\circ} \mathrm{C}$, and $100^{\circ} \mathrm{C}$ and an overall air flow rate of $20 \mathrm{~L} / \mathrm{min}$. This gives an air flow rate of $12 \mathrm{~cm} / \mathrm{min}$. Based on the inlet air temperature and humidity, the $\mathrm{RH}$ in the oven was approximately $3 \% \mathrm{RH}$ at $60^{\circ} \mathrm{C}$ and less than $1 \% \mathrm{RH}$ at $80^{\circ} \mathrm{C}$ and $100^{\circ} \mathrm{C}$. Liquid marbles were dried for at least 12 hours to ensure complete drying.

Once dried, the granules were removed from drier and classified visually into categories and counted. To minimize inconsistency, all analysis for each powder/binder combination was performed on the same day. Pictures of the hollow granules were taken with a stereo microscope (SMZ series) with a 3MP Motic camera. The internal structure of selected granules was analyzed using an XUM x-ray microscopy.

The effects of changing the drying temperature, powder type and size, binder type and binder concentration were studied to determine the best drying conditions. The matrix of data was first analyzed for each binder solution at different drying temperatures to find the most suitable 
temperature for drying liquid marbles regardless of binder and powder type. Then, the effect of binder and powder type at two selected drying temperatures $\left(60^{\circ} \mathrm{C}\right.$ and $\left.100{ }^{\circ} \mathrm{C}\right)$ were examined.

\section{Results}

During experiments we observed that if the liquid droplet was covered with only a thin or mono layer of powder, all the liquid marbles collapsed during drying regardless of temperature, binder and powder type. Survival of hollow granules was generally observed when there was a thick powder layer around the droplet. In practice during granulation in high shear mixers, it can be assumed that all droplets will have a multi-layer of powder as a result of the frequent collision with powders in the highly agitated powder motion in granulator. Moreover, anecdotal observations suggested that smaller the droplet size, the higher the chance of hollow granule survival. This is consistent with previous reports of collapsed granules occurring mainly in the larger granule sizes [1]. Drop sizes are in a granulation process are much smaller, typically $100-500 \mu \mathrm{m}$, so the liquid marble survival results in this study represent a worst case scenario.

In our analysis we consider two criteria: "survivability" and "quality" of the hollow granules. "Survivability" refers to the propensity of the liquid marbles to form hollow granules, i.e. to avoid collapse during drying. "Quality" of the hollow granules refers to their shape. A variety of different shapes were observed after drying: collapsed granules which often formed an annular blood cell shape; buckled hemispherical granules with one or more depression; and perfect hemispherical granules. 
Figure 3 shows several examples of each type. In a few cases, perfect spherical granules were formed. The success of a given drying condition is a combination of how well the drying condition supports both survivability and quality.

X-ray microscopy was used to confirm that the spherical or hemispherical granules formed after drying were hollow, as shown in Figures 4, 5, and 6. Figure 6 clearly shows the hollow structure as the absence of particles in the interior of the shell is obvious. X-ray microscopy was conducted only on glass ballotini and Aerosil granules as a confirmation of visual observations. The remaining granules are assumed to be hollow or collapsed based on the shape of the exterior.

A systematic set of experiments was performed with different binder types and powders, at a range of different drying temperatures. Table 1 summarizes the overall results of these experiments, and indicates the dependency of stability and shape of the hollow granules on the drying temperature, and powder / binder combination.

From Table 1, PVP polymer was not able to stabilize glass ballotini liquid marbles at any tested drying temperature, but $\mathrm{HPMC}$ polymer was successful at $100^{\circ} \mathrm{C}$ and $\mathrm{HPC}$ above $80^{\circ} \mathrm{C}$. Maintaining a hollow granule throughout the drying process appears to be aided by higher drying temperatures. All the tested binders were able to make hollow granules with Aerosil at drying temperatures above $60^{\circ} \mathrm{C}$. The results in Table 1 imply that the ability to form hollow granules after drying depends on both binder type and drying temperature. 
The stability of the hollow granule appears to depend on the powder used as indicated by Walton and Mumford [10], as different drying temperatures are required for each powder to ensure hollow granule survival. For example, glass ballotini hollow granules survive above $80^{\circ} \mathrm{C}$ while Aerosil granules survive as long as the drying temperature is above $60^{\circ} \mathrm{C}$. Moreover, by increasing temperature from $60^{\circ} \mathrm{C}$ to $100^{\circ} \mathrm{C}$ the shape of hollow granule gradually improves until a perfect hemisphere is reached (see Table 1). This result shows that the final quality of the hollow granules depends on both the drying temperature. At higher drying temperatures, quick removal of the interior liquid improves the stability of hollow structure. The receding surface of the drying droplet does not generate as much capillary stress on the particle shell. It may also form a rigid porous shell at higher drying temperatures (as per case Ia in Figure 1) and form a pliable shell (see case III in Figure 1) at lower drying temperatures [9].

To find a general trend for drying liquid marbles it is necessary to examine a matrix of data for different binder/powder combinations at two selected temperatures- $60^{\circ} \mathrm{C}$ and $100^{\circ} \mathrm{C}-$ which had shown reasonable hollow granule formation after drying in the preliminary drying studies in Table 1. Each binder-HPMC, PVP, HPC- is discussed individually below before analyzing the overall trends observed during the experiments.

\subsection{HPMC binder}

As the HPMC binder concentration increased, the survivability of the liquid marbles improved as well as the quality of the hollow granules. As shown in Figure 7, by increasing HPMC concentration from $5 \%$ to $18 \%$ the proportion of perfect hollow granules increased from $19 \%$ to $72 \%$ and the percentage collapsed was reduced from 58\% with 5\% HPMC to $0 \%$ with $18 \%$ HPMC. This result is 
consistent with the previous study reported by Walton and Mumford [10] as they reported that by increasing the concentration the particle distortion and surface rupture decreased. The Formation rate for buckled granules was unaffected over the concentration tested. Data in Figure 7 is a combination of result for all powders- Aerosil, glass beads and PTFE - at both drying temperatures - $60^{\circ} \mathrm{C}$ and $100^{\circ} \mathrm{C}$.

Figure 8 illustrates how increasing the concentration of HPMC affected the quality of hollow granules formed from Aerosil. The 12\% HPMC granule (left) is almost a hemisphere and has a hole in the base. In contrast, the granule formed from 18\% HPMC (right) is noticeably more spherical and has no hole in the base. Some of the produced hollow granules produced with 18\% HPMC had odd striped patterns on their surface (see Figure 9). The striated surface may be the first step toward buckling. As the overall shape of these hollow granules was still hemispherical, these hollow granules were classed as hemispherical rather than buckled.

Increasing the drying temperature from $60^{\circ} \mathrm{C}$ to $100^{\circ} \mathrm{C}$ improved the success rate for hollow granule formation using HPMC binder across all powders (Figure 10). For example, with 8\% HPMC dried at $100^{\circ} \mathrm{C}$ exhibited less collapsing compared to drying at $60^{\circ} \mathrm{C}$. It appears that increasing the drying temperature does not significantly affect the proportion of buckled granules. Figure 10 shows a steady amount of buckled hollow granules across HPMC $8 \%$ to $18 \%$, while the amount of collapsed granules decreases and the number of perfect granules increases. Thus, increasing the drying temperature considerably improves both the survivability and quality of hollow granules formed with HPMC as a binder. 
Increasing the drying temperature at higher HPMC concentrations (12 \&18\%) had little effect on the quality or survivability (see Figure 10). When the desired hollow granule is achieved at a lower temperature, there is no advantage in increasing the drying temperature further.

Figure 11 shows the survivability and quality of HPMC granules as a function of the powder used. Data for all HPMC concentrations and both drying temperatures have been combined to show the overall trend in Figure 11.

Overall, Aerosil is clearly most successful powder in terms of survivability as well as the quality of formed hollow granule. The loosely aggregate floc-like structure of the nano-sized silica particles creates a highly porous shell and consequently increases the chance of survival (see case I in Figure 1). These resilient Aerosil liquid marbles are consistent with reports by Bhosale et al. [7] that nanosized Aerosil forms stronger liquid marbles compared to larger size particles. This is demonstrated in Figure 11, where Aerosil is produces a very high proportion of perfect hemispherical hollow granules compared to PTFE and glass beads as these liquid marbles will withstand higher compressive stresses and tensile loads [7], as experienced during drying.

It was expected that as particle size decreased, the chance of survival would increase as small particles are subjected to less gravity force due to the reduced weight of the small particles. However, for PTFE powder, the largest PTFE $100 \mu \mathrm{m}$ powder was the most successful, then the $12 \mu \mathrm{m}$ and $1 \mu \mathrm{m}$ size grades, and finally the $35 \mu \mathrm{m}$ size grade which was the least successful. The $12 \& 1 \mu \mathrm{m}$ size grades of PTFE may form better multilayered powder shells due to their cohesiveness and this would improve the survivability. The PTFE 100 may also provide good 
coverage as each particle was large and the particles were observed to pack fairly densely in the powder shell, leaving relatively only small regions of the droplet surface uncovered. The chance of survival of the liquid marbles will be high as powder creates a uniform particle layer in the liquidvapor interface [7]. These factors would explain the apparent superiority of 100, 12, and 1 micron PTFE powders over the 35 micron size grade, which was neither large nor cohesive and could not achieve good liquid coverage.

\subsection{PVP binder}

Increasing the PVP binder concentration also increased the success rate for hollow granule formation. As shown in Figure 12, increasing the concentration of PVP from 5\% to 18\% improved survivability. Increasing the binder concentration had only a slight effect on the quality of the granules formed, as there is no significant change in the number of perfect hollow granule across 5 to $18 \%$ PVP concentration.

Increasing the drying temperature from $60^{\circ} \mathrm{C}$ to $100^{\circ} \mathrm{C}$ improved PVP hollow granule survival by decreasing the number of collapsed granules and increasing number of buckled granules across all PVP concentrations (Figure 13 ).

From Figure 14, Aerosil was the most successful powder (see lowest left image in Figure 3) with PVP binder, and glass ballotini was the least successful. Hollow PVP granules are most likely to survive if the particle size is small - the nanosized Aerosil R974 produced $100 \%$ perfect granules and the $1 \mu \mathrm{m}$ and $12 \mu \mathrm{m}$ grades of PTFE had high survival rates close to $50 \%$. For glass ballotini neither increasing binder concentration nor increasing drying temperature could produce any form of 
hollow granule. The complete collapse under all conditions implies that some property of the glass powder - perhaps the higher density - is incompatible with PVP binder which corresponds with Walton and Mumford [10] study that the final morphology of particles depends on chemical and physical nature of the skin material. In summary, the survival of PVP hollow granules improves as the particle size decreases, the drying temperature increases and as the concentration of PVP increases.

\subsection{HPC binder}

Figure 15 summarizes whether a hollow granule survived during drying process as a function of HPC binder concentration across all used powders and drying temperatures. As the HPC concentration increases from $5 \%$ to $18 \%$, the number of collapsed granules remains almost constant but the quality improves as shown by the decreasing number of buckled granules and increasing number of perfect hollow granules. Above 10\% HPC concentration, it seems that the quality of the formed granules decreases while the number of collapsed granules remains constant. In other words, increasing HPC concentration above $10 \%$ causes previously perfect hollow granules to start buckling. This implies that there is a limit in increasing the concentration of binder (see Figure 15) and that there is an optimum binder viscosity and/or surface tension which occurs at 8-10\% HPC.

Figure 16 and Figure 17 summarize hollow granule survivability during drying, as a function of HPC concentration and temperature for ballotini and Aerosil. Higher HPC concentrations are expected to produce stronger hollow granules due to a stronger and denser network of solid bridges

which form during the drying process. The lowest HPC concentration of $2 \%$ was not able to properly assemble particles together to prevent collapsing the liquid marble during drying, even at the highest 
drying temperature $\left(100^{\circ} \mathrm{C}\right)$ with Aerosil (see Figure 16). These figures show that there is a minimum concentration of HPC required to avoid granule collapse, and that the minimum HPC concentration varies for each different powder. For example, 5\% HPC could stabilize hollow granules of Aerosil R974 (Figure 16) at $60^{\circ} \mathrm{C}$, but a higher concentration of HPC (10\%) was needed to maintain the hollow structure for glass ballotini (Figure 17) at the same temperature. The reason for this phenomenon may be related to the particle size and density, as larger and denser glass particles would need higher binder concentration to provide enough inter-particulate bonds to withstand the gravitational forces.

Increasing the concentration of HPC binder also affects the hollow granule shape. As can be seen in Figure 17, by increasing the concentration of HPC binder, more "perfect" granules - including a full "base" are formed from glass ballotini. For instance, by increasing the HPC concentration from $8 \%$ to $10 \%$, just over $50 \%$ of the hollow granules formed from glass ballotini had a full base at $100^{\circ} \mathrm{C}$. By further increasing the HPC concentration to $18 \%$, all of the formed granules had a base (see Figure 17). The reason why no bases were formed for Aerosil granules despite a wide range of HPC concentrations is not clear.

The survivability of hollow granule dried at lower temperatures can be increased if the HPC concentration is increased. From Figure 17 for glass ballotini and up to 8\% HPC in binder, all glass ballotini liquid marbles dried at $60^{\circ} \mathrm{C}$ collapsed. By increasing the binder concentration from $8 \%$ to $10 \%$ and $12 \%$, the hollow granule survival rate after drying at $60^{\circ} \mathrm{C}$ increased $30 \%$ and $60 \%$, respectively. 
Figure 16 and Figure 17 show that the survivability and quality of the hollow granules is different for each powder. PTFE $100 \mu \mathrm{m}$ powder performed the best with HPC binder in terms of survivability and the proportion of perfect hemispherical shaped granules, compare to the smaller PTFE grades (see Figure 18). Figure 18 also shows that Aerosil performs better than other powders, perhaps due to its nano particle size or the low density of the fractal particle aggregates. Although hydrophobic glass ballotini particles are smaller $(65 \mu \mathrm{m})$ than PTFE $100 \mu \mathrm{m}$ and lighter, hollow granule formation was less successful with glass ballotini which indicates the significance of careful powder selection.

In summary, Aerosil R974 was the most successful powder with HPC, and increasing HPC concentration improved the hollow granule quality. The effect of increasing the drying temperature was mixed.

\section{Discussion}

\subsection{Comparing all three binders: HPMC, PVP and HPC}

HPMC appeared to be the best binder as it worked well across the various powders and temperatures (see Figure 19). HPC and PVP seemed to both perform poorly in comparison. However they seemed to complement each other in their response to different conditions: HPC performed well with the glass ballotini whilst PVP didn't, and vice versa with respect to the PTFE 1 and PTFE 12 powders. 
In general, increasing temperature increases survivability in all cases (see Figure 10 and Figure 13) and improves significantly the quality of granules formed with HPMC (see Figure 10). Temperature had no significant effect on the quality of hollow granules formed with PVP (see Figure 13) and HPC (data not shown). There may be a viscosity effect involved, as the PVP was much less viscous than HPC and HPMC. For comparison, Figure 20 shows the survivability of hollow granules as a function of viscosity for different concentrations of HPMC, PVP and HPC binders. As shown in Figure 20, for PVP and HPMC there is a consistent proportional relationship between binder fluid viscosity and the proportion of formed hollow granule. In order for a liquid marble to collapse, the drop must deform which requires internal fluid flow. We propose that higher viscosities binder fluids resist this flow and therefore enhances liquid marble stability during drying. However, for HPC, the average survival rate remains relatively constant between $40-50 \%$ regardless of the HPC concentration or viscosity. This may be related to precipitation of HPC and decreasing solubility of polymer in water at higher temperature. HPC is freely soluble in water below $38^{\circ} \mathrm{C}$, forming a smooth, clear, colloidal solution and changes to a swollen floc at a temperature between 40 and $45^{\circ} \mathrm{C}$ [12]. HPC precipitates out when the temperature increases above the cloud point, where the hydrogen bonds between water and the polymer chains become less favorable. .The solubility of the HPC in water then decreases and a polymer-rich phase precipitates [11] which affects the uniformity of the polymeric bridges formed during drying. For example, the cloud point of a 250 ppm HPC solution is $43.5^{\circ} \mathrm{C}$ [11] well below even the lowest drying temperature of $60^{\circ} \mathrm{C}$. As the polymer concentration decreases, the cloud point increases [11]. This may at least partly explain why increasing HPC concentration caused previously perfect hollow granules to start buckling, as the lower cloud point caused earlier precipitation of the HPC which adversely affected the survival rate. 
Aerosil was the most successful powder for forming perfect hollow granules with all the binders tested (see Figure 21 ). However, there were some exceptions at higher binder concentration (18\% $\mathrm{HPC}$ and $18 \% \mathrm{HPMC}$ ) and at the highest drying temperature $100^{\circ} \mathrm{C}$. The most successful combination was 12\% HPMC binder using Aerosil R974 dried at $100^{\circ} \mathrm{C}$. The results for glass ballotini had mixed success. It was highly unsuccessful with PVP, moderately successful with the HPMC/HPC and did better at higher temperatures. PTFE powders had mixed success again but at least some of the grades worked with all binders.

Figure 22 shows the effect of PTFE particle size on the hollow granule survival rate for the three tested binder fluids. For PVP, there is a critical particle size somewhere between $12 \mu \mathrm{m}$ and $35 \mu \mathrm{m}$ where only hollow granules formed from particles smaller than this size can survive. HPMC also shows a sharp drop in survival rate for PTFE35, although the survival rate then rebounds for the large PTFE 100 particles. In contrast, HPC shows a high success rate only for the largest PTFE particles.

When drying marbles formed with high binder concentrations, in some instances a higher drying temperature induced collapsing or buckling. At higher binder concentrations, the fluid viscosity could be quite high which causes the droplets to be slightly larger and thus more prone to deformation during the drying process. When dried at $60^{\circ} \mathrm{C}$, more shrinkage of the liquid marbles occurred (see Figure 23) and this may have increased survivability, as opposed to $100^{\circ} \mathrm{C}$ where shrinkage would occur less. Thus, the beneficial effects of drying at a lower temperature when using high concentrations of binder may be due to the enhanced shrinkage and strengthening of the liquid 
marble during drying. These points at least partly explain the unexpected lack of success at high binder concentrations and higher drying temperatures for both HPMC and HPC binders.

\subsection{Particle size effect}

As drying continues the particles pack closely enough that inter-particle repulsions resist further shrinkage [13]. The binder, however, continues to vaporize through the holes between the particles [8]. The decrease in binder volume causes the receding of the drying surface into the droplet. Buckling of liquid marble can then occur because decreasing droplet pressure exerts a compressive capillary stress on the particle shell. When this stress becomes large enough to overcome the repulsive forces between the particles the outer shell undergoes buckling and wrinkling. It is clear inter-particle forces play an important role in determining droplet buckling, and any other ingredients in the particle shell can affect these forces and the buckling behavior of liquid marble. Polymers are an example of material that can significantly change the interaction between solid particles [13].

Aerosil was the most successful powder with all of binders, presumably because the interparticle forces between the nano particles are high and able to resist the capillary stress. This is in agreement with previous study by Bhosale et al. [7] who indicated that the loosely aggregate floclike structure of the nano-sized silica particles creates a highly porous shell and consequently increases the chance of survival. This hypothesis also agrees with case I in Figure 1 by Charlesworth \& Marshall [9]. 


\subsection{Shrinkage of liquid marble during drying}

During drying of the liquid marbles, the droplet shrinks and the final granule size is smaller than the original droplet. The level of shrinkage depends on the drying temperature. Figure 23 shows two granules of Aerosil with $8 \% \mathrm{HPC}$ dried at $60^{\circ} \mathrm{C}$ and $100^{\circ} \mathrm{C}$. Although their initial primary droplet size was the same, it is clearly seen that the granule dried at $60^{\circ} \mathrm{C}$ is smaller than granule size at $100^{\circ} \mathrm{C}$. The higher drying temperature creates a granule size more comparable with primary droplet size. This can be seen as an additional variable requiring control, or as an additional variable which can be used to manipulate the granule size. We expect that the granules shown in Figure 23 would also have different granule strengths, due to both the physical size and the film thickness, although we have not performed any experiments to test this to date.

\subsection{Implications of liquid marble drying behaviour}

We have previously postulated a series of steps for liquid marble formation and for hollow granule formation [1]. The final step was that "the multi-component powder shell must be sufficiently strong to be self-supporting in order to avoid collapse during drying to form a hollow sphere and subsequent standard powder handling operations" [1]. Qualitatively, the drying behavior of liquid marbles is in agreement with the types of drying behaviors observed by Charlesworth \& Marshall [9] and shown in Figure 1. All crust structures except IIC were observed during this study. We conclude that the optimal drying conditions for liquid marbles are driven by similar mechanisms for drying of solute drops, except that liquid marbles begin the drying process with a powder shell "crust" already in place. This observation should be of practical use during formulation and product development of cosmetic and pharmaceutical products based on liquid marbles and hollow granules. 


\section{Conclusion}

The optimal condition for stabilizing liquid marbles during drying and formation of hollow granules were investigated for several types of powder and binder at different drying temperatures. Higher drying temperature, smaller or nano-size particles and higher binder concentration tend to promote the formation of perfect hollow granules. It was found the survival rate was directly proportional to binder viscosity for HPMC and PVP. However; for HPC binder the survival rate was essentially constant regardless of HPC concentration. Different combinations of drying temperature, binder type, binder concentration, and powder type/grade could result in quite large changes in survival rate indicating the importance of careful formulation during hollow granule process development.

\section{Acknowledgements}

This project is financially supported by Australian Research Council under Discovery Projects DP0770462. Scholarship support for N. Eshtiaghi was provided by Monash Graduate Research School. We express our grateful thanks to Sherry Mayo for taking x-ray microscopy photo of our samples in Manufacturing and Material Technology Group of CSIRO lab.

\section{References}

[1] K. P. Hapgood, L. Farber, JN. Michaels, Agglomeration of hydrophobic powders via solid spreading nucleation, Powder Technology, 188 (2009), 248-254.

[2] P. Aussillous, D. Quere, Liquid marbles, Nature 411 (2001) 924-927. 
[3] P. Aussillous, D. Quere, Properties of liquid marbles, Proceedings of Royal Socierty A, 462 (2006), 973-999.

[4] L. Forny, K. Saleh, I. Pezron, P. Guigon, L. Komunjer, Influence of mixing characteristics for water encapsulation by self-assembling hydrophobic silica nanoparticles Powder Technology, special issue on granulation, 189 (2009), 263-269.

[5] M. A. Ansari, F.Stepanek, Formation of hollow core granules by fluid bed in-situ melt granulation: Modelling and experiments, International Journal of Pharmaceutics, 321 (2006) 108-118.

[6] K. P. Hapgood, B. Khanmohammadi, Granulation of hydrophobic powders, Powder Technology, 188 (2009), 248-254.

[7] P. S. Bhosale, M. V. Panchgnula, H. A. Stretz, Mechanically robust nanoparticle stabilized transparent liquid marbles, Applied Physics Letters 93 (2008) 034109/1- 034109/3.

[8] M. Dandan, H.Y. Erbil, Evaporation rate of graphite liquid marbles: comparison with water droplets, Langmuir (2009), DOI: 10/1021/la900729d

[9] D. H. Charlesworth, W. R. J. Marshall, Evaporation from drops containing dissolved solids, AIChE Journal 6 (1960) 9-23.

[10] D.E.Walton, C.J. Mumford, The morphology of spray-dried particles: the effect of process variables upon the morphology of spray-dried particles, Chemical Engineering Research \& Design 77 (1999) 442-460

[11] F. M. Winnik, Effect of temperature on aqueous solutions of pyrene-labled (Hydroxypropyl) cellulose, Macromolecules 20 (1987) 2745-2750

[12] R.J. Harwood, "Hydroxypropyl Cellulose", in Handbook of Pharmaceutical Excipients, $5^{\text {th }}$ edition, R.C. Rowe, P.J. Sheskey and S.C. Owen (eds), Pharmaceutical Press, London, 2006. 
[13] Y. Sugiyama, R.J. Larsen, J. Kim, D. A. Weitz, Buckling and crumpling of drying droplets of colloid-polymer suspensions, Langmuir 22 (2006) 6024-6030

\section{List of Figures:}




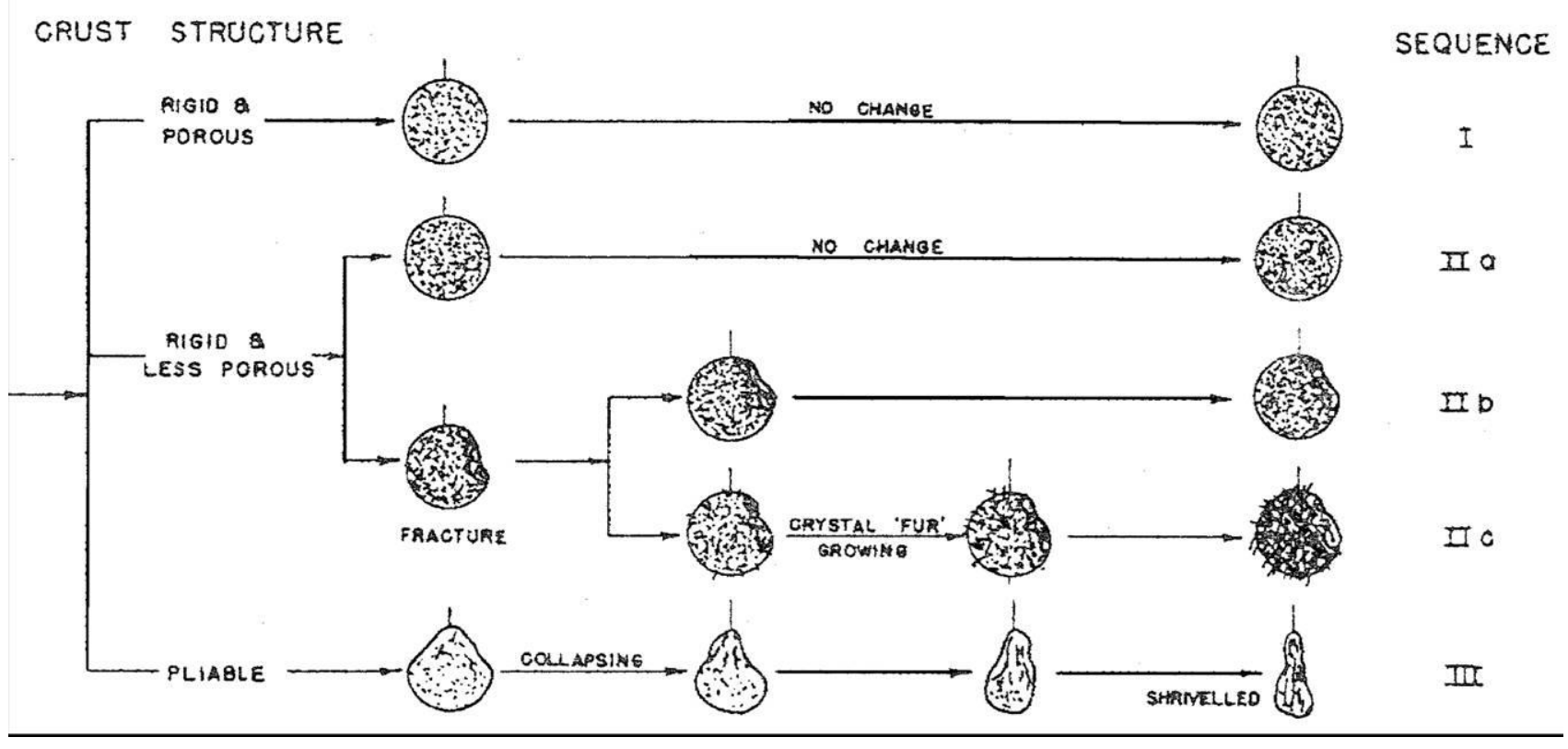

Figure 1. Selected structures formed after drying of a single droplet below the boiling point of the solution [8]

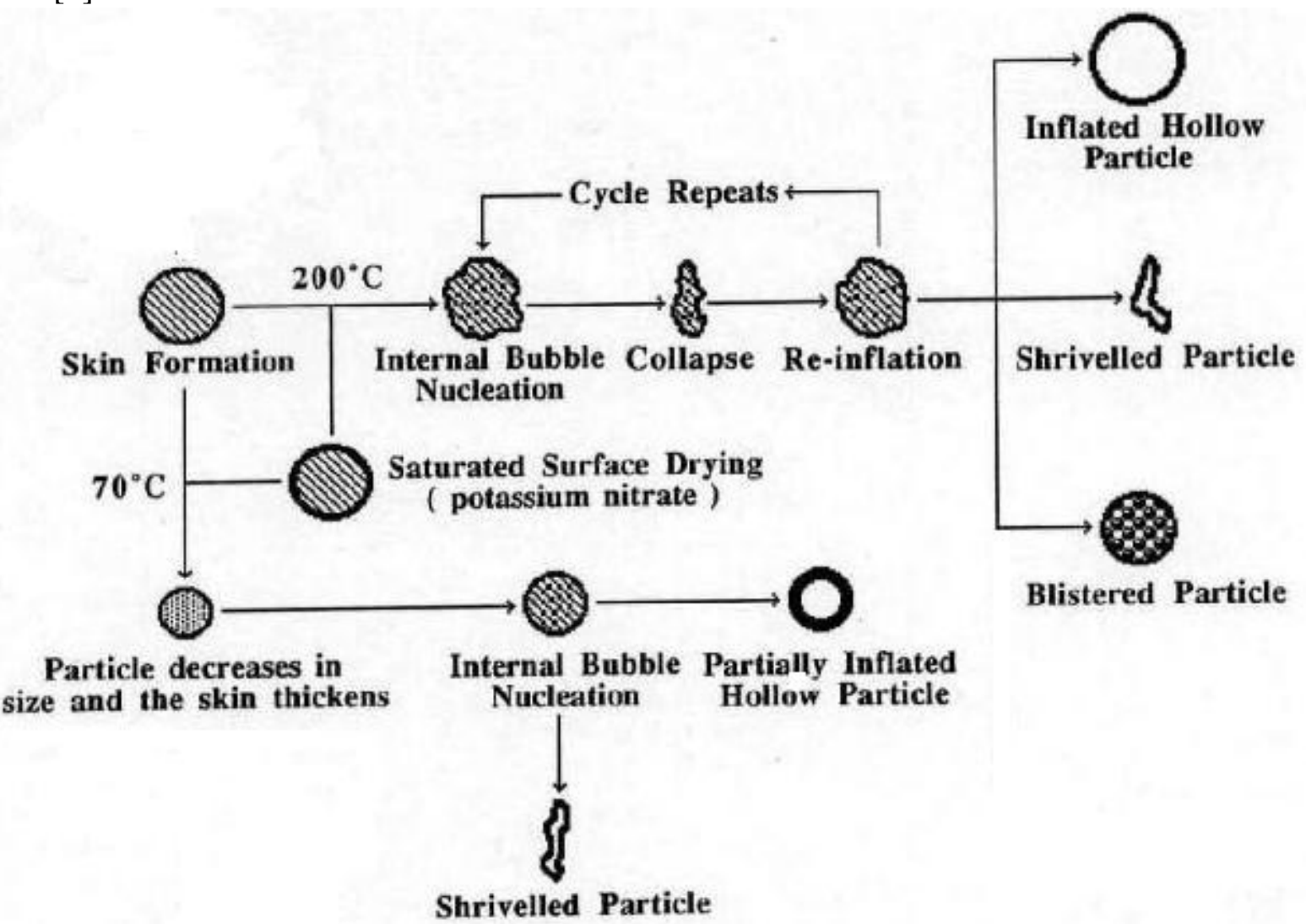

Figure 2. Selected different particle morphologies formed after drying of a single droplet at $70^{\circ} \mathrm{C}$ and $200{ }^{\circ} \mathrm{C}[10]$ 


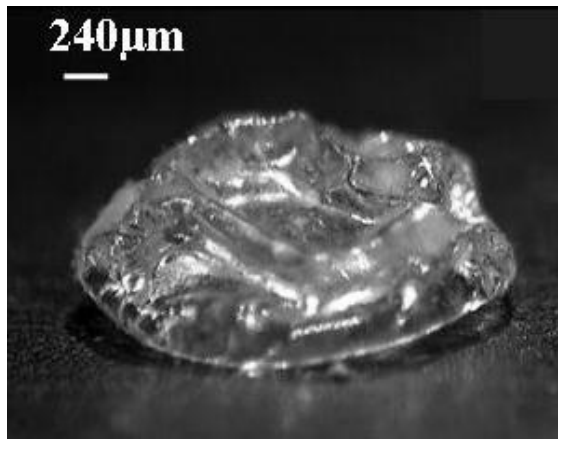

Aerosil \& $18 \% \mathrm{HPC}$ at $100^{\circ} \mathrm{C}$

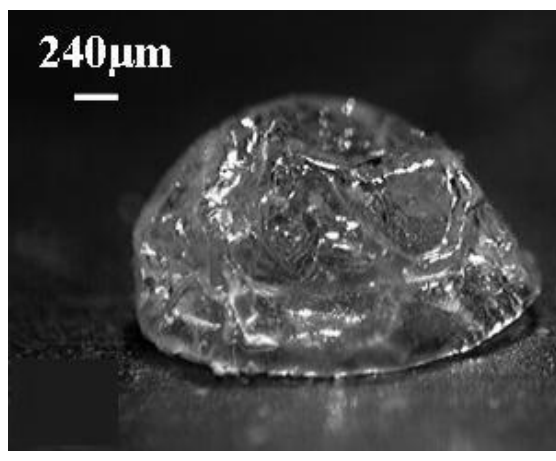

Aerosil \& $12 \% \mathrm{HPC}$ at $100^{\circ} \mathrm{C}$
(a)Collapsed

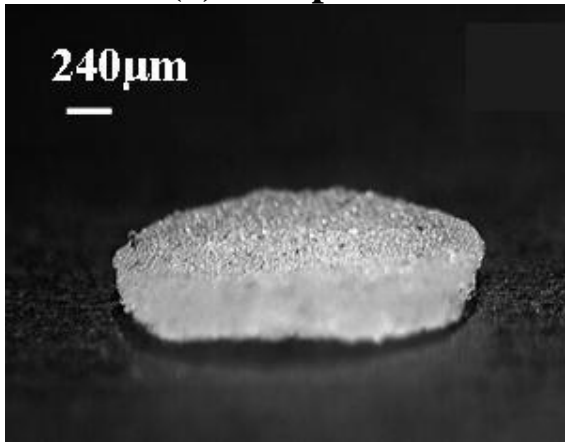

Ballotini \& $8 \%$ PVP at $60^{\circ} \mathrm{C}$

(b)Buckled

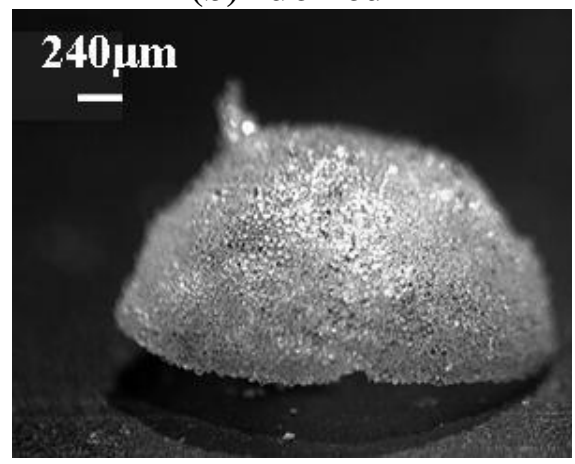

Ballotini \& $10 \% \mathrm{HPC}$ at $100^{\circ} \mathrm{C}$ (c)Perfect

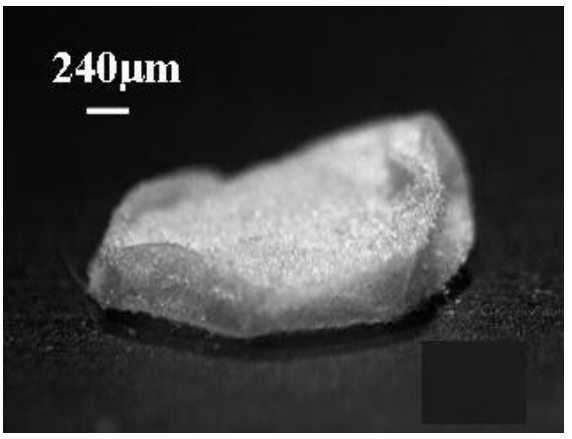

PTFE $35 \& 5 \% \mathrm{HPC}$ at $100^{\circ} \mathrm{C}$

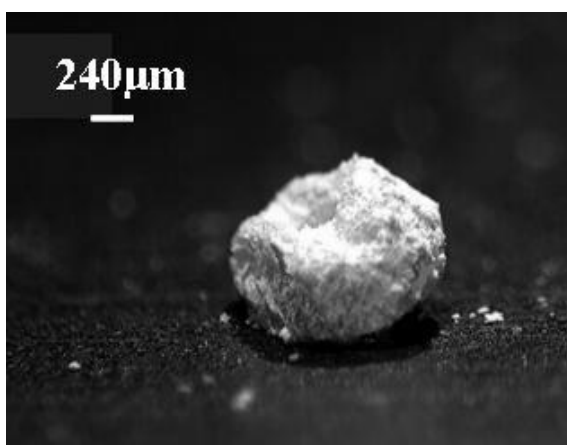

PTFE $12 \& 8 \% \mathrm{HPMC}$ at $60^{\circ} \mathrm{C}$ 


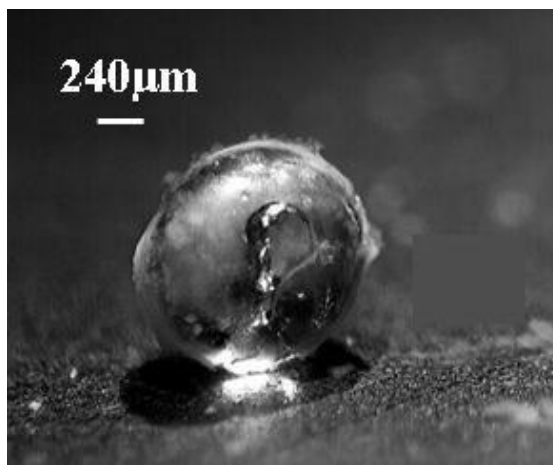

Aerosil \& $18 \% \mathrm{PVP}$ at $100^{\circ} \mathrm{C}$

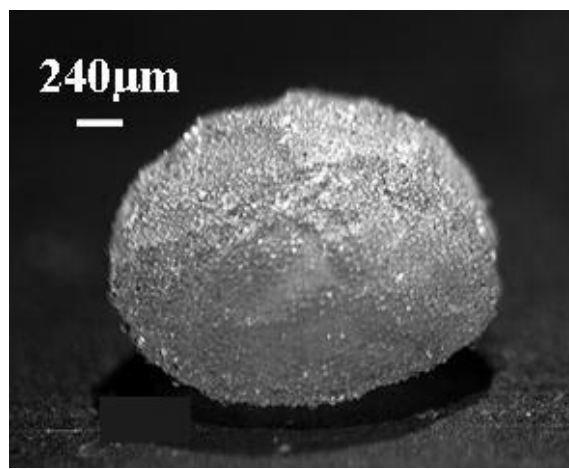

Ballotini\&12\% $\mathrm{HPMC}$ at $100^{\circ} \mathrm{C}$ PTFE $100 \& 18 \% \mathrm{HPC}$ at $100^{\circ} \mathrm{C}$

Figure 3. Formed hollow granule structure of Aerosil R974, hydrophobic glass ballotini (AG) and PTFE powder (a) collapsed (b) buckled (c) perfect

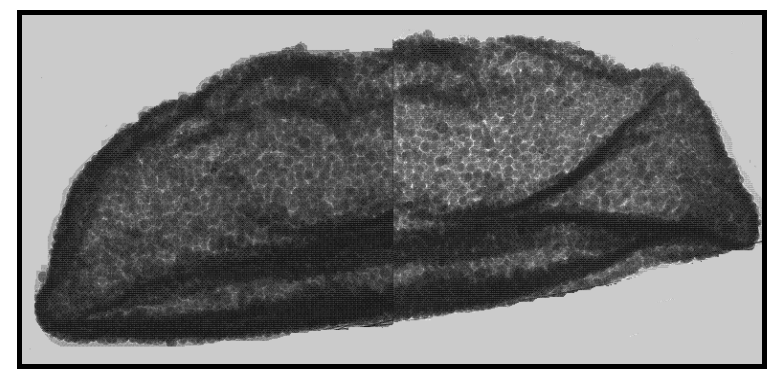

Figure 4. X-ray microscopy image of a buckled hollow hemisphere granule (3mm Diameter) made from hydrophobic glass ballotini and $10 \% \mathrm{HPC}$ dried at $60^{\circ} \mathrm{C}$

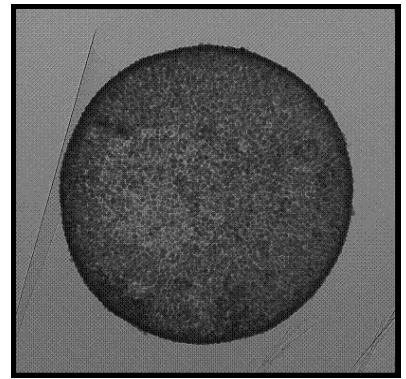

(a)

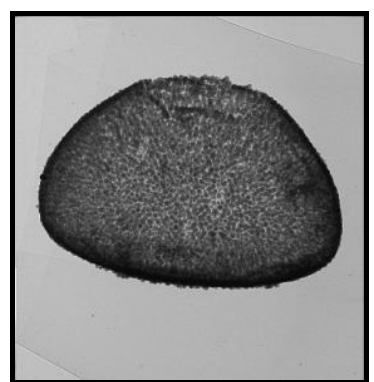

(b)

Figure 5. X-ray microscopy image of hollow spherical granule (2-3mm Diameter). Hydrophobic glass ballotini and $10 \% \mathrm{HPC}$ dried at $100^{\circ} \mathrm{C}$ (a) top view, (b) side view 


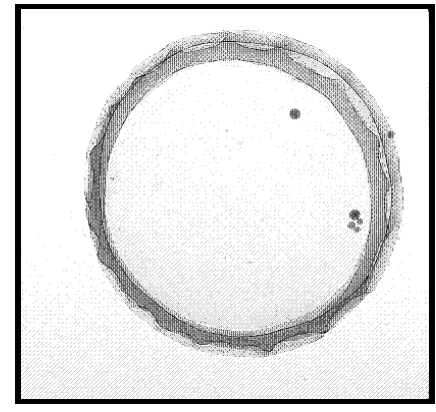

(a)

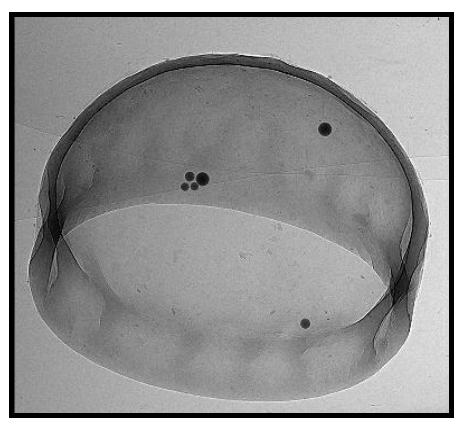

(b)

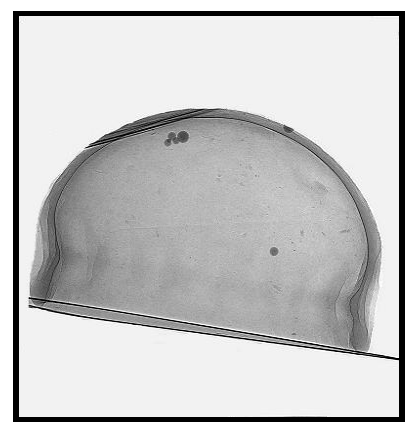

(c)

Figure 6. X-ray microscopy image of hollow hemispherical granule (2-3mm Diameter) of Aerosil R974 and 8\% HPC from, (a) top view, (b) bottom view, (c) side view 


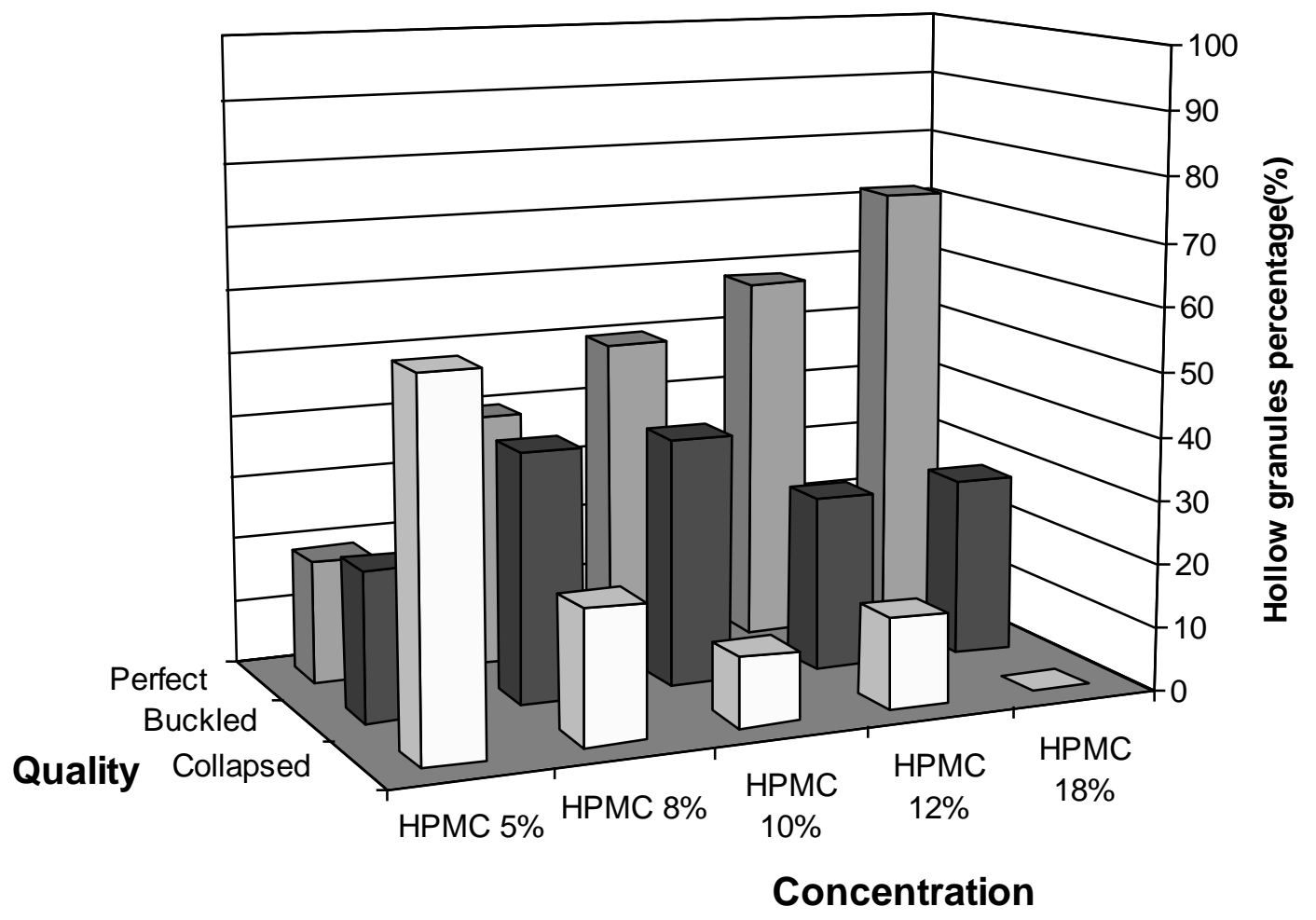

Figure 7. Effect of increasing HPMC binder concentration. Graph combines data for all powders and both drying temperatures.

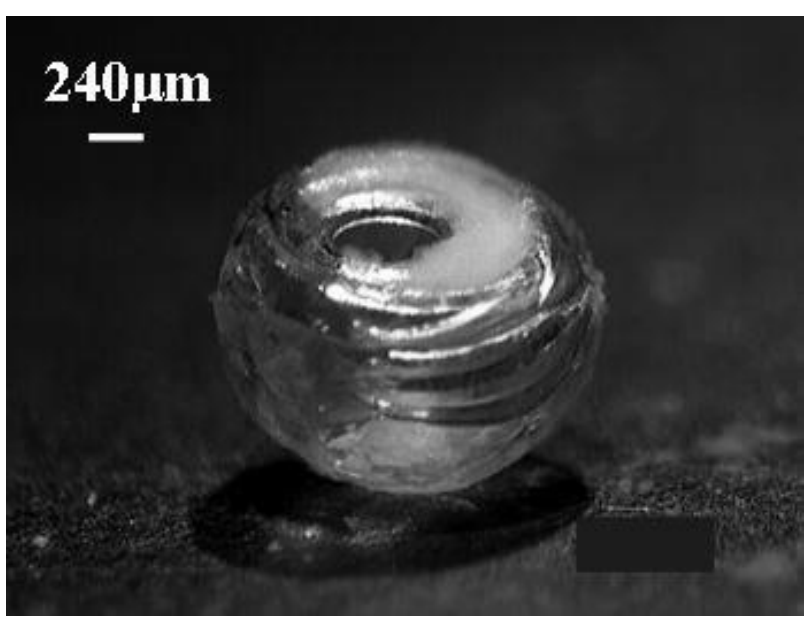

(a)

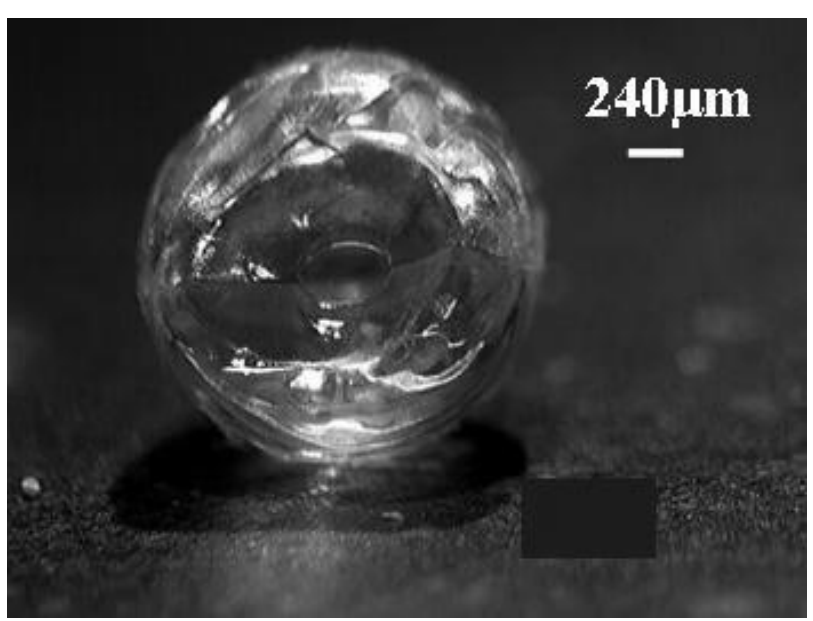

(b)

Figure 8. Hollow granules formed at $100^{\circ} \mathrm{C}$ from Aerosil R974 and (a) $12 \% \mathrm{HPMC}$, (b) $18 \% \mathrm{HPMC}$ 


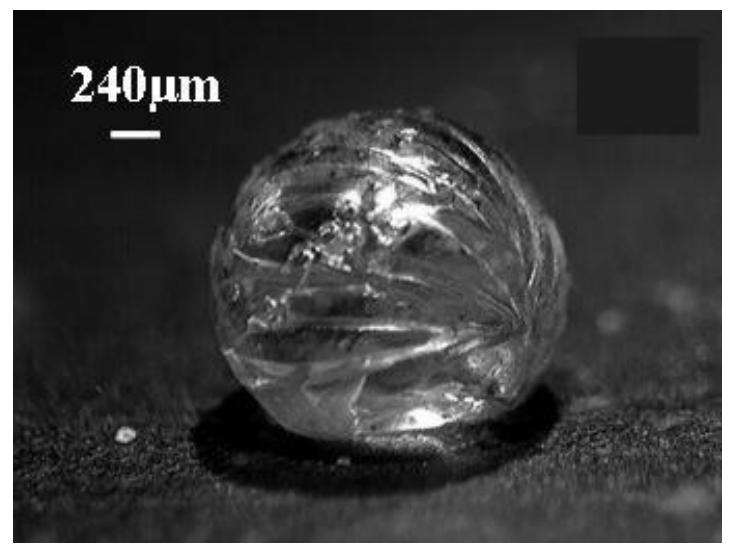

Figure 9. Hollow granule formed with Aerosil R974 and $18 \%$ HPMC dried at $100^{\circ} \mathrm{C}$ showing striated surface.

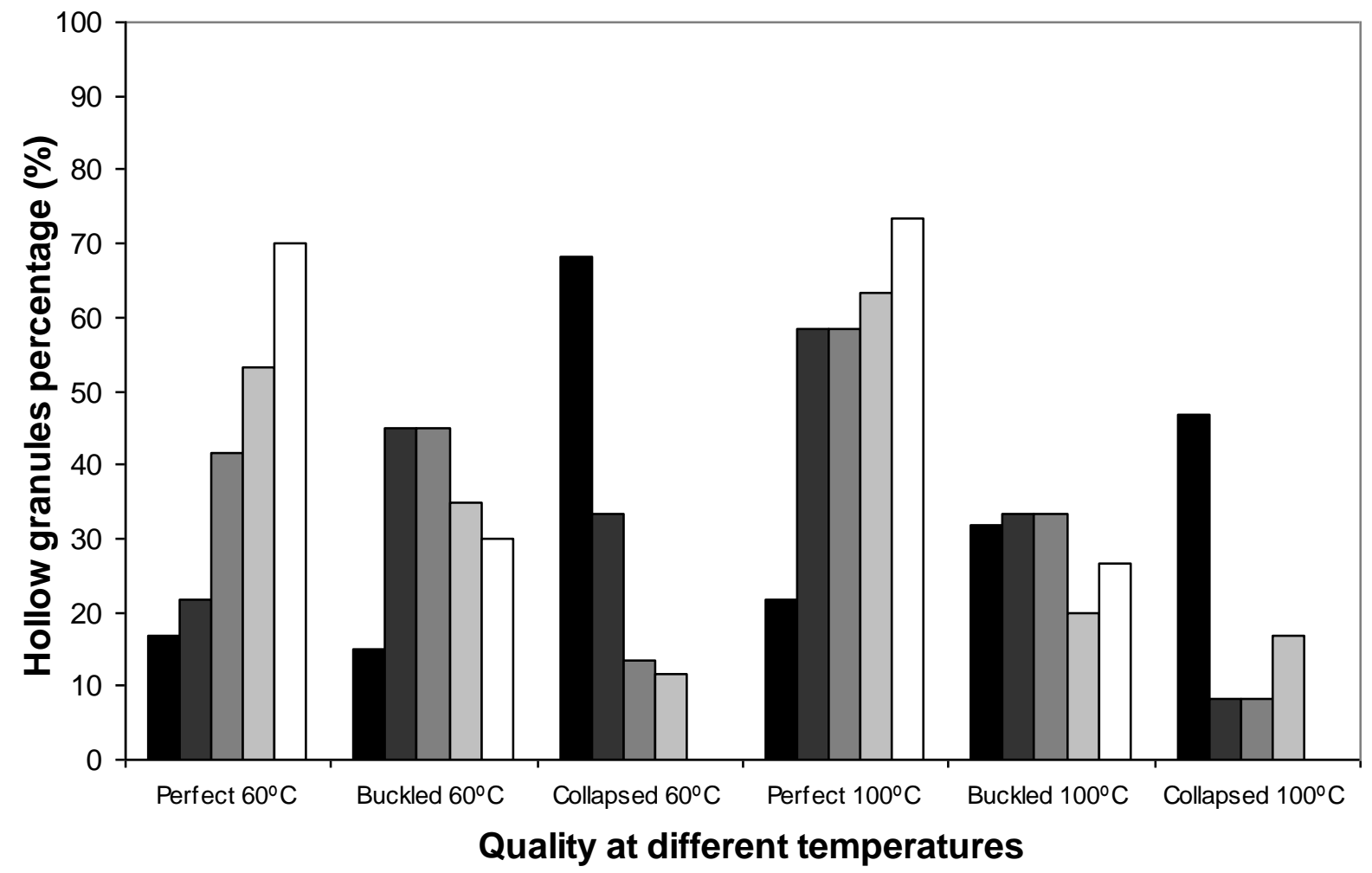

$\begin{array}{lllll}\text { a HPMC } 5 \% & \text { aHPMC } 8 \% & \text { 口HPMC } 10 \% & \text { 口HPMC } 12 \% & \text { 口HPMC } 18 \%\end{array}$

Figure 10. Effect of HPMC concentration and drying temperatures on survivability and quality of hollow granules (graph includes data for all used powders). 


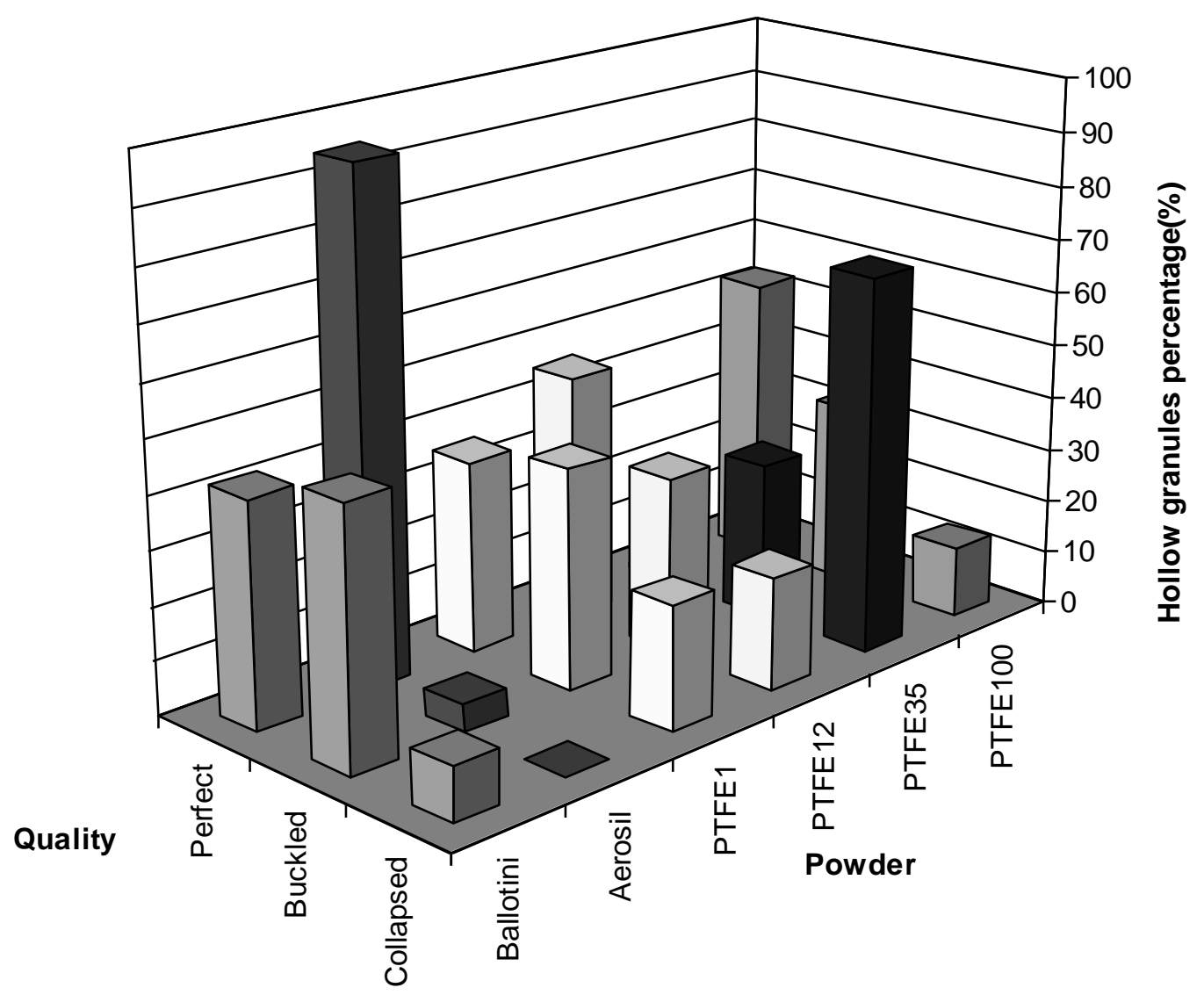

Figure 11. Effect of powder type on hollow granule survivability and quality. Data for all HPMC concentrations and drying temperatures have been combined. 


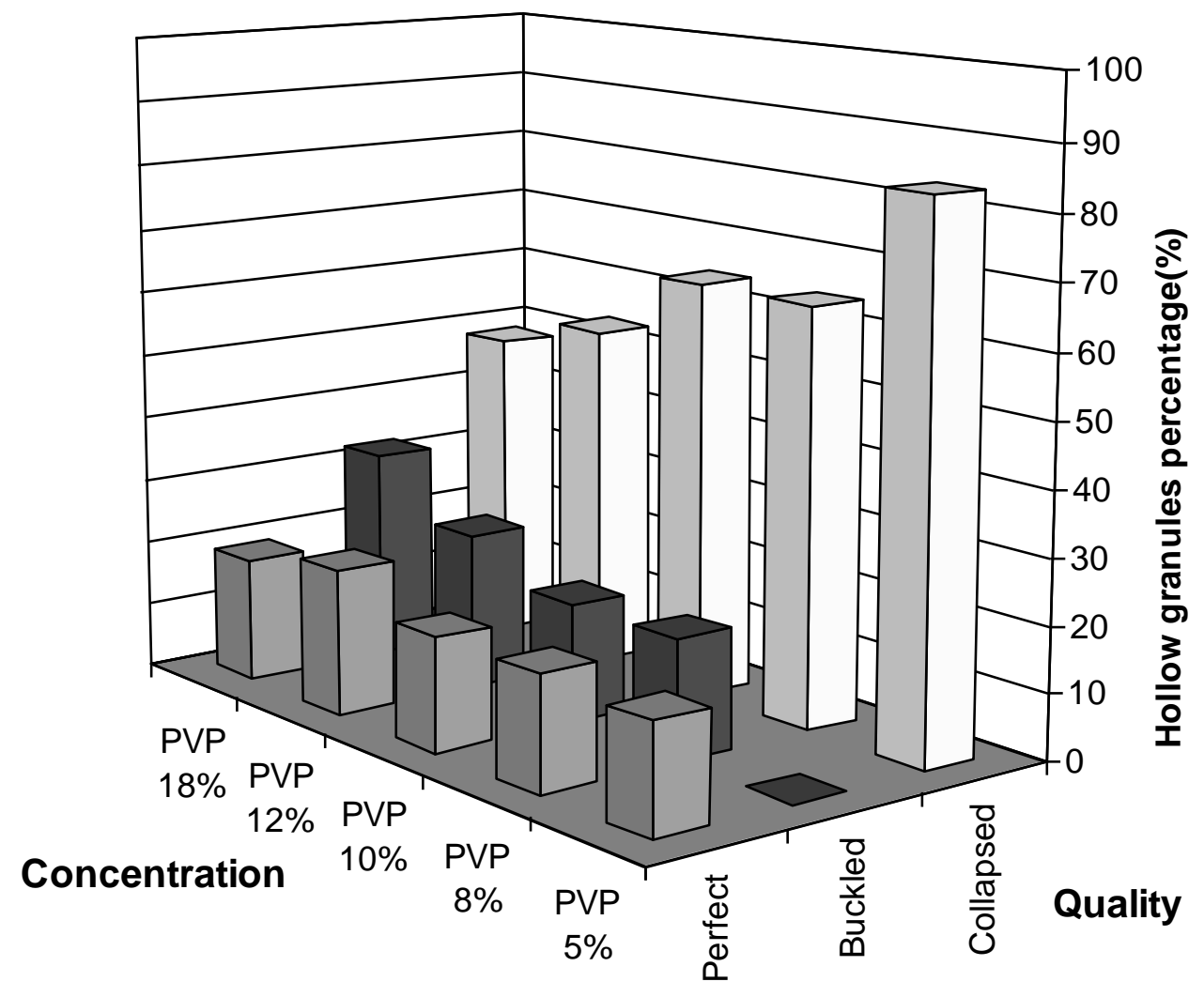

Figure 12. Effect of increasing PVP binder concentration on survivability of hollow granule (graph includes data for all used powders and both drying temperature: $60^{\circ} \mathrm{C} \& 100^{\circ} \mathrm{C}$ ) 


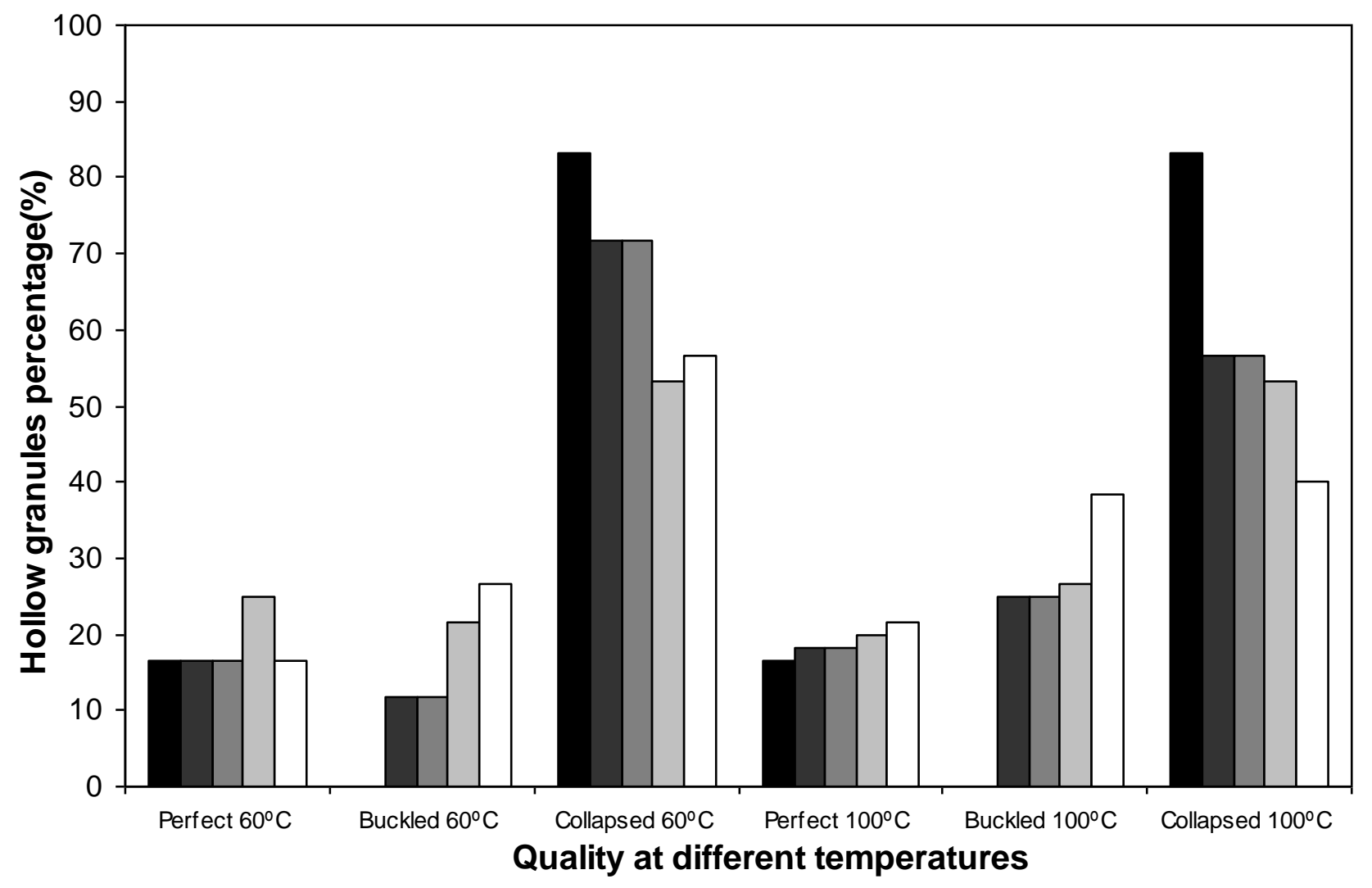

\begin{tabular}{|c|c|c|c|c|}
\hline PVP $5 \%$ & 口PVP 8\% & 口PVP 10\% & 口PVP $12 \%$ & 口PVP 18\% \\
\hline
\end{tabular}

Figure 13. Effect of increasing drying temperature on survival of hollow granules using PVP binder. 


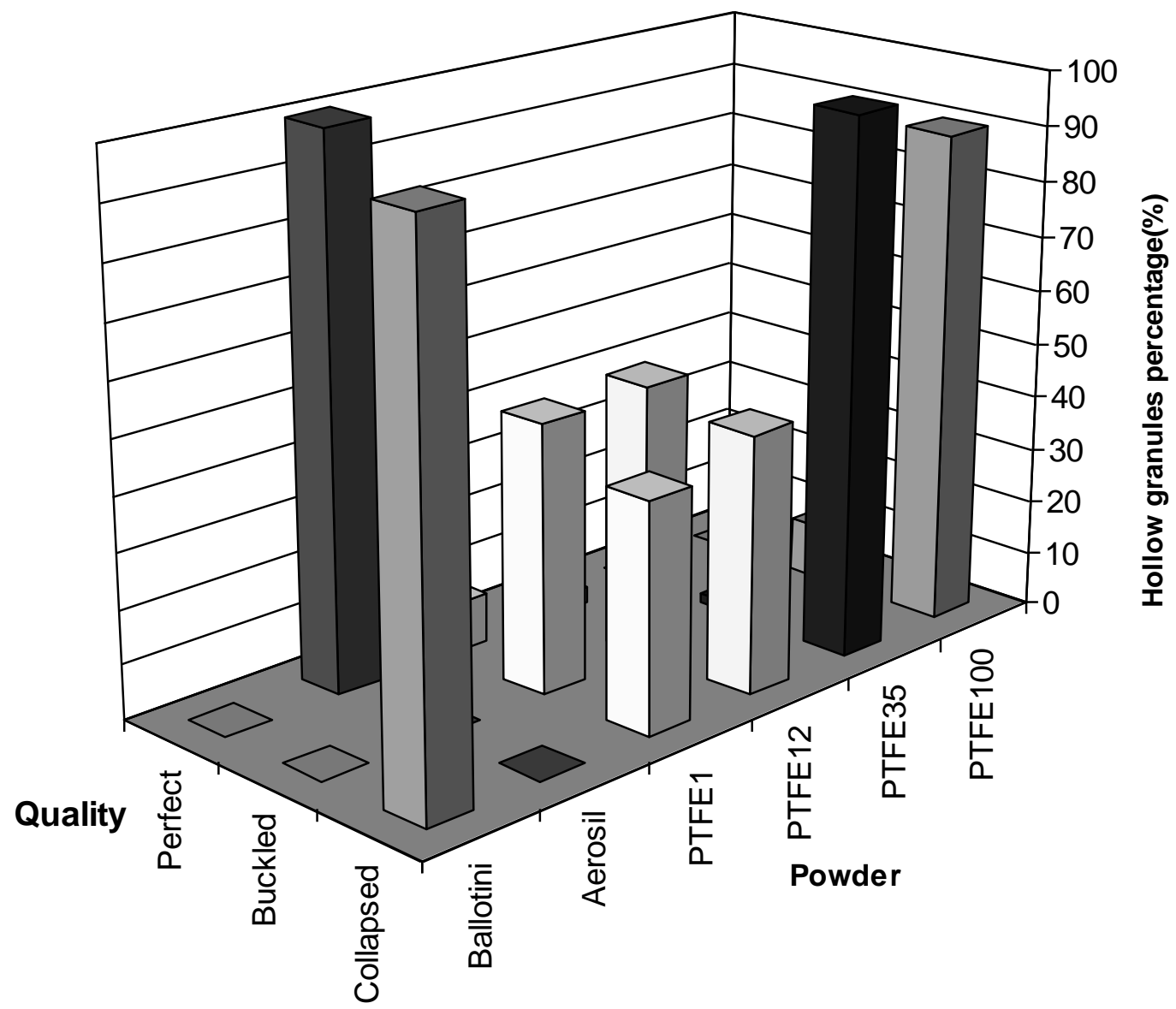

Figure 14. Effect of powder type on survivability of hollow granule. Data from all PVP concentrations and both drying temperatures have been combined. 


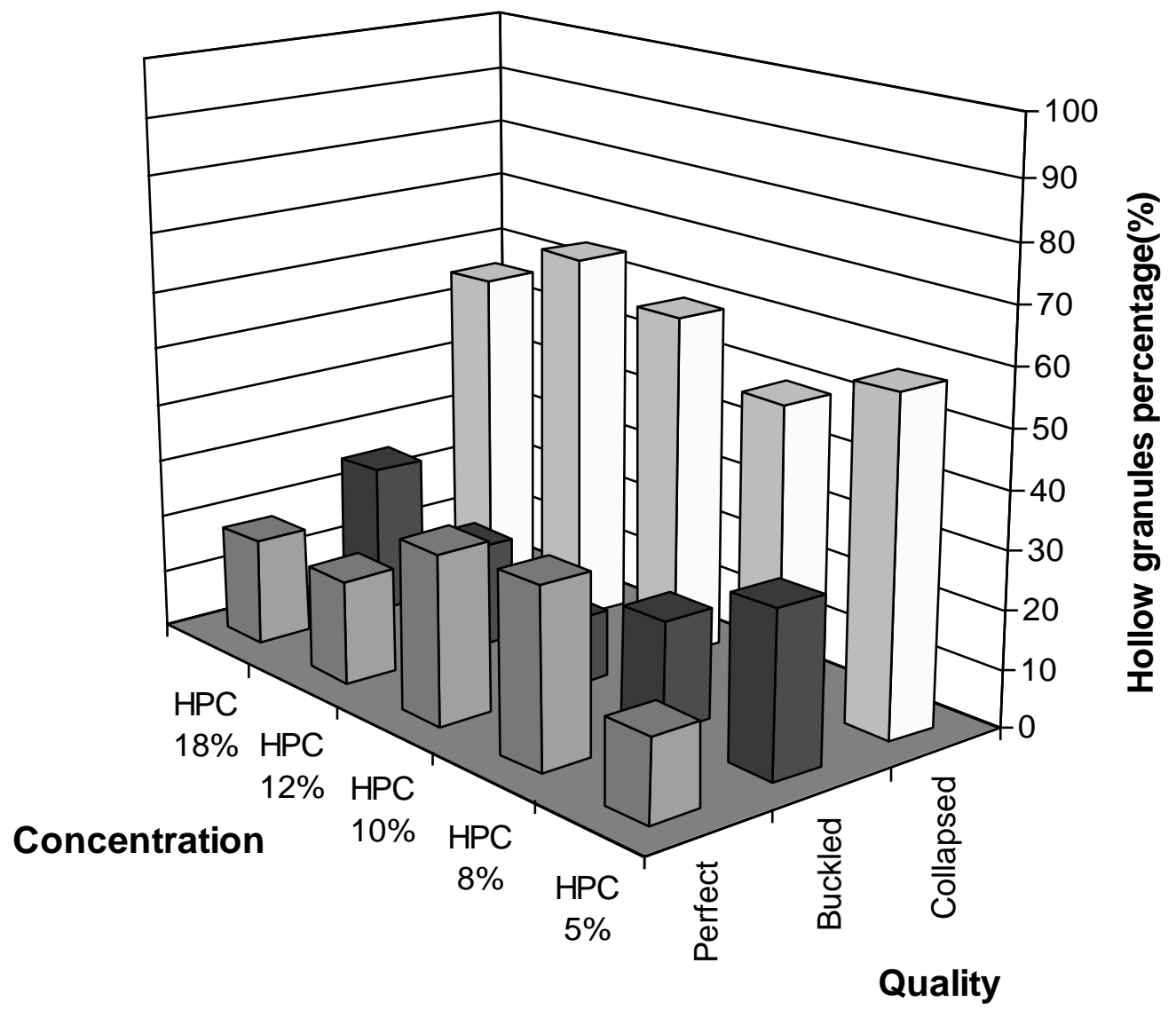

Figure 15. Effect of HPC concentration on the hollow granule quality (graph combines data for all powders and both drying temperatures) 


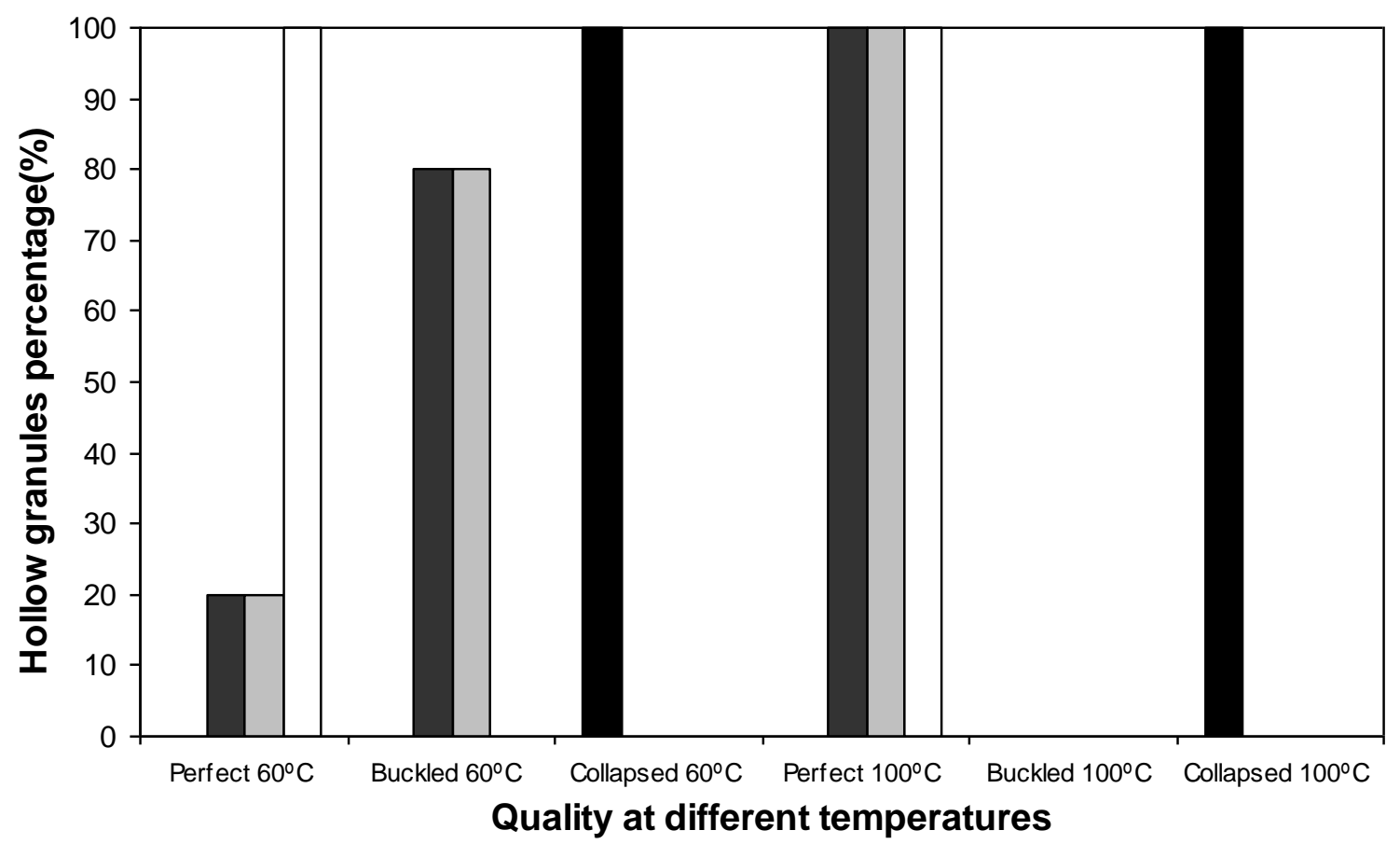
Quality at different temperatures
- HPC $2 \%$
口HPC $5 \%$
口HPC $8 \%$
口HPC $10 \%$

Figure 16. Effect of HPC concentration on quality of Aerosil R974 hollow granule (graphs combines data for both drying temperatures) 


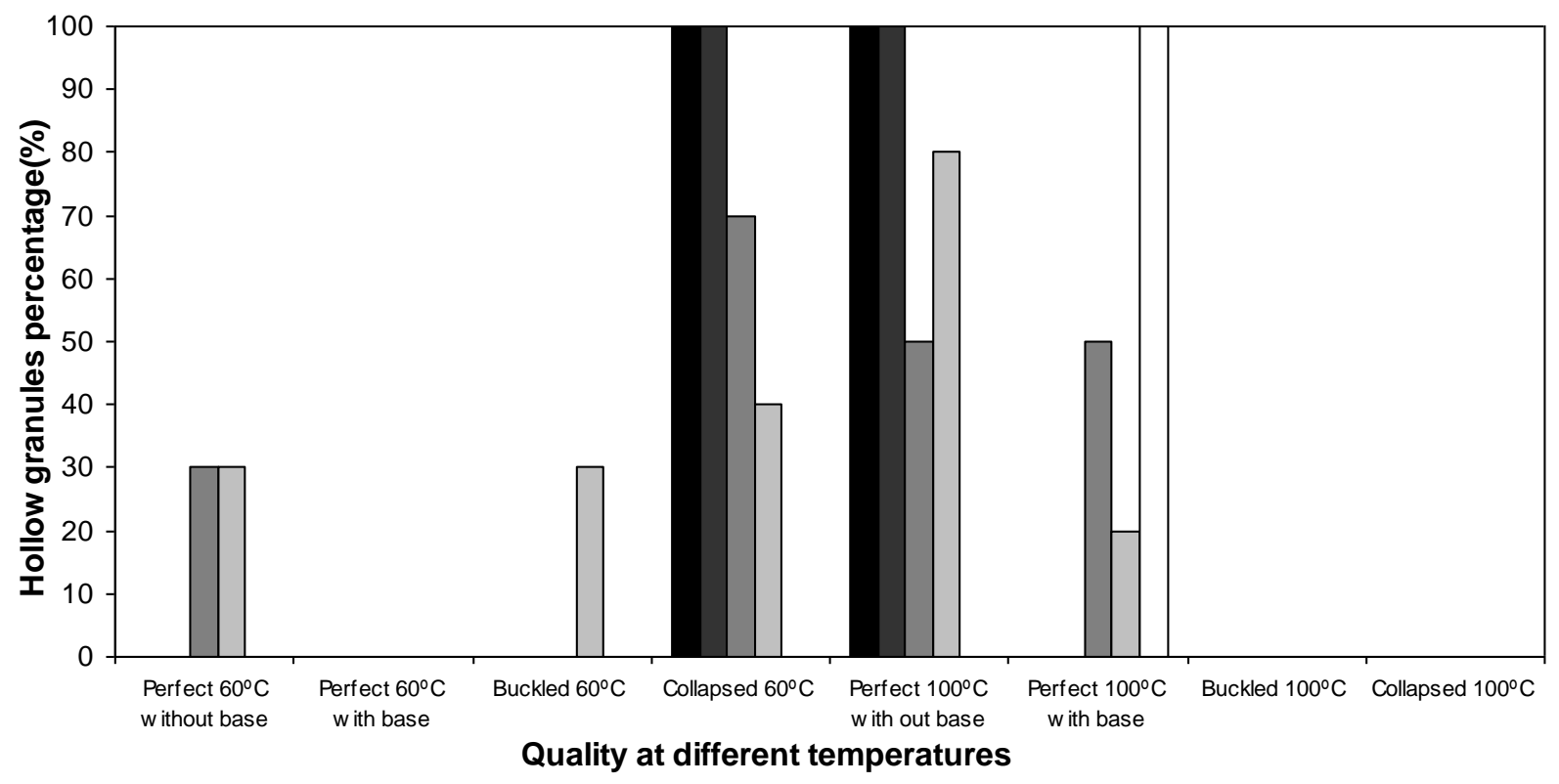

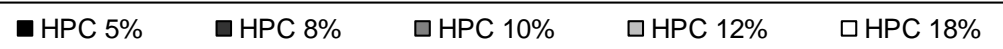

Figure 17. Effect of HPC concentration on quality of glass ballotini hollow granules (graph combines data for both drying temperatures) 